\title{
Karakteristik Tanah Longsor di Daerah Aliran Sungai Tangka
}

\author{
Usman Arsyad ${ }^{1 *}$, Roland Barkey ${ }^{1}$, Wahyuni ${ }^{1}$, Karla Kembongallo Matandung ${ }^{2}$ \\ ${ }^{1}$ Staf Pengajar Departemen Kehutanan, Fakultas Kehutanan, Universitas Hasanuddin \\ 2Alumni Fakultas Kehutanan, Universitas Hasanuddin \\ *Email: usman.arsyad@yahoo.co.id
}

\begin{abstract}
Landslides occur as a result of ground movement on steep slopes, and the high humidity (moisture), and the sparse vegetation (open land). The Local conditions is an interrelated components. The process of landslides can be explained that the water soak into the soil will add weight to the ground. If the water penetrates the soil acts as a watertight sliding plane, the ground becomes slippery and soil weathering on it will move to follow the slope. This study aims to determine the type of landslide, landslide characteristics and landslides causing factors. This research was conducted in September 2015 in Watershed Tangka. The study consisted of three stages, namely the determination of the coordinates of the location of the landslide, landslide determining the location of the sample, the determination of the type of landslide, slope measurements, measurements of the dimensions of landslide and infiltration. Research results obtained are the coordinates of the location of as many as 17 points landslide, landslide types of translation and rotation, land cover and soil texture. There is no difference in the type of soil, infiltration rate, vegetation, geologi, slope and rainfall in both types of landslide are found.
\end{abstract}

Keywords: landslide, types, characteristics, Tangka Watershed

\section{PENDAHULUAN}

Bencana alam merupakan peristiwa alam yang dapat terjadi baik secara tiba-tiba maupun yang berlangsung perlahan, dimana saja dan kapan saja, yang menimbulkan kerugian materil dan nonmateril. Tanah longsor merupakan salah satu bencana alam yang telah banyak menimbulkan kerugian harta benda, korban jiwa, kerusakan sarana dan prasarana lainnya yang berdampak pada kondisi sosial masyarakatnya.. Pertambahan luas lahan kritis, erosi, banjir, sedimentasi dan tanah longsor merupakan indikator tentang menurunnya daya dukung DAS. Kondisi DAS yang cenderung memburuk menyebabkan peristiwa erosi, banjir, sedimentasi dan tanah longsor akhir-akhir ini semakin sering terjadi dan cenderung meningkat. Untuk itu dibutuhkan penanganan yang menitikberatkan langsung pada masalahnya, agar kualitas suatu DAS dapat sesuai dengan harapan.

Salah satu permasalahan yang cukup serius adalah tanah longsor. Bencana tersebut tidak hanya menyebabkan kerugian materil, tetapi juga memakan korban jiwa yang tidak sedikit. Penyebab longsor utama adalah adanya gaya gravitasi yang mempengaruhi suatu lereng curam, namun tidak menutup adanya faktor-faktor lain yang menyebabkan terjadinya longsor, seperti curah hujan yang tinggi, penggunaan lahan yang kurang tepat dan struktur geologinya. Lahan terbuka semakin bertambah luas dari tahun ke tahun yang mendorong semakin bertambahnya lahan kritis. Apabila terdapat lapisan kedap air di bawah permukaan tanah dan tidak adanya vegetasi yang menjadi pengikat lapisan kedap air, maka hal itu yang memicu terjadinya longsor pada daerah yang memiliki kelerengan curam.

DAS Tangka adalah salah satu DAS yang mencakup 3 kabupaten yaitu, Kabupaten Bone, Kabupaten Gowa dan Kabupaten Sinjai yang mempunyai luas $\pm 47.504,86$ ha. DAS Tangka merupakan salah satu DAS yang berpotensi menimbulkan terjadinya bencana alam berupa tanah longsor terutama di bagian hulu. Pada tahun 2014 wilayah DAS Tangka terjadi bencana tanah longsor. Kejadian ini merupakan bencana terbesar yang pernah terjadi di Dusun Patalassang yang menghancurkan puluhan hektar sawah, kebun warga. Longsor, dua jembatan utama, turbin Pembangkit Listrik Tenaga Mikro Hydro (PLTMH) dan satu mobil angkutan milik desa tetapi tidak ada korban jiwa (Candra,2014).

Karakteristik longsor yang terjadi di DAS Tangka perlu diketahui agar besarnya bahaya tanah longsor dapat diminimalisir. Oleh karena itu, dilakukan penelitian yang berjudul "Karakteristik Tanah Longsor di DAS Tangka". 


\section{METODE PENELITIAN}

\subsection{Waktu dan Tempat}

Penelitian ini dilakukan di DAS Tangka pada bulan September - Desember 2015 pada tiga kabupaten yaitu Kabupaten Bone, Gowa dan Sinjai Provinsi Sulawesi Selatan.

\subsection{Prosedur Penelitian}

Pada tahap awal penelitian, dilakukan kegiatan berupa penentuan titik koordinat lokasi kejadian longsor.Titik lokasi kejadian tanah longsor diperoleh dari interpretasi citra google earth (Rekaman 13, September 2014) berdasarkan pola dan karekteristiknya yaitu rona, warna dan tekstur. Koordinat titik longsor yang didapat pada citra google earth diamati dilapangan untuk mengetahui apakah longsor tersebut benar-benar terjadi. Titik koordinat lokasi penelitian ditentukan dengan menggunakan GPS.Titik ini berguna untuk pembuatan peta titik lokasi kejadian longsoran.

Data dari setiap titik kejadian tanah longsor diketahui melalui pengukuran-pengukuran sebagai berikut :

\section{a. Penentuan Lokasi Longsoran Sampel}

Penentuan lokas sampel dilakukan dengan membagi tiga wilayah yaitu titik longsoran sampel pada bagian hilir, bagian tengah dan bagian hulu DAS. Penentuan ini berdasarkan karakteristik biogeofisiknya seperti, kelerengan dan kerapatan drainasenya. Daerah hulu memiliki kelerengan lebih besar dari 15\% dan kerapatan drainase tinggi, lembah/sungai berbentuk huruf "V" dan aliran airnya deras. Bagian tengah memiliki kelerengan $8 \%-15 \%$, kerapatan drainase sedang, umumnya landa dengan penampang lembah berbentuk huruf " $U$ " dan banyak terdapat anak-anak sungai dengan aliran sungai berkelok-kelok. Bagian hilir memiliki kerapatan drainase kecil dan memiliki kelerangan lebih kecil dari $8 \%$ terletak di daerah landai dan mendekati laut. Umumnya terdapat di daerah dataran rendah dan aliran sungai sangat lambat Setelah dilakukan penentuan lokasi longsoran sampel penelitian kemudian dilakukan pengukuran di longsoran tersebut.

\section{b. Penentuan Jenis Longsoran}

Penentuan jenis longsoran dilakukan dengan melihat bentuk dan material di daerah longsoran. Jenis longsoran diketahui dengan cara sebagai berikut : 1). Jenis longsoran translasi diketahui dengan melihat bidang gelincir pada longsoran yang berbentuk rata atau menggelombang landai dengan material tanah dan batuan, 2). Jenis longsoran rotasi diketahui dengan melihat bidang gelincir yang berbentuk cekung dengan material tanah dan batuan, 3). Jenis pergerakan blok diketahui dengan melihat perpindahan blok batu dari bidang miring, seperti bentuk patahan yang terpisah, 4).Jenis runtuhan batu diketahui dengan melihat sejumlah besar batuan atau materil lainbergerak ke bawah dengan cara jatuh bebas. Umumnya jenis ini terjadi pada daerah pantai, 5). Rayapan tanah diketahui dengan melihat adanya objek yang tertanam pada tanah, yang dalam jangka waktu cukup lama mengalami perubahan bentuk menjadi miring karena adanya pergeseran tanah dengan material tanah, batuan, tiang listrik, rumah dan lain sebagainya, 6). Aliran bahan rombakan diketahui dengan melihat material longsoran yang berasal dari lereng bagian atas dan meluas pada daerah landai.

\section{c. Pengukuran Kelerengan}

Kelerengan diukur menggunakan abney level dalam derajat $\left(^{\circ}\right)$ kemudian dikonversikan menjadi satuan persen (\%). Pengukuran dilakukan pada daerah yang belum terjadi longsor dalam hal ini yang dimaksudkan yaitu lereng asli. 


\section{d. Pengukuran Dimensi Longsoran (panjang dan lebar)}

Pengukuran dimensi longsoran dengan menggunakan meteran. Panjang longsoran yang diukur adalah jarak antara bagian atas dan bagian bawah longsoran, lebar longsoran yang diukur adalah jarak horisontal bagian atas dan bagian bawah longsoran.

\section{e. Pengukuran Infiltrasi}

Pengukuran laju infiltrasi dengan menggunakan metode penggenangan pada tanah yang tidak longsor. Alat yang digunakan adalah double ring infiltrometer. Titik tempat pemasangan dibersihkan dari rumput dan tanaman pengganggu, kemudian ring dibenamkan ke dalam tanah sampai separuh dari tinggi alat dengan kedudukan diusahakan tegak lurus jangan sampai rusak atau pecah-pecah (Maniskari, 2013). Sebelum penuangan air pada silinder tengah, silinder luar diisi air supaya perembesan kearah luar bisa dikurangi, ring tengah harus selalu terisi air selama proses pengamatan. Pengamatan penurunan air dilakukan tiap menit hingga 10 menit sampai penurunan air dalam silinder konstan. Kekurangan air selalu ditambah dan selalu dijaga agar ring tidak dalam keadaan kosong serta dibaca batas penambahannya sampai penurunannya konstan.

\section{f. Pengambilan Sampel Tanah}

Pengambilan sampel tanah dilakukan dengan mengambil sampel pada tanah yang belum terjadi longsor kemudian dimasukkan ke dalam plastik dan diberi label selanjutnya, dianalisis di Laboratorium Silvikultur Universitas Hasanuddin untuk mengetahui tekstur danstruktur tanah pada lokasi longsoran. Dari seluruh titik kejadian longsor terdapat 6 sampel tanah yang diamati.

\section{g. Pengambilan Material Longsoran (batuan)}

Pengambilan material longsoran dilakukan untuk mengetahui jenis material (batuan) longsoran yang ditemukan pada lokasi kejadian longsoran.

\section{h. Vegetasi}

Untuk pengamatan vegetasi pada lokasi kejadian longsor dilakukan dengan melihat penutupan lahan dan jenis tanaman apa saja yang terdapat pada daerah sekitar longsoran. Hal ini penting untuk mengungkapkan bahwa kejadian longsor umumnya ditemukan pada penutupan lahan tertentu saja atau tidak.

\section{HASIL DAN PEMBAHASAN}

Dari penelitian yang dilakukan, ditemukan 17 titik lokasi longsoran.Sebaran titik longsoran berdasarkan ketinggian dari hilir ke hulu adalah 289-2439 m dpl.Uraian lengkap dari semua titik longsoran tersebut disajikan pada Tabel 1.

Tabel 1. Sebaran titik koordinat dan ketinggian lokasi longsoran di DAS Tangka

\begin{tabular}{|c|c|c|c|c|c|}
\hline \multirow{2}{*}{ No } & \multirow[b]{2}{*}{ Label } & \multicolumn{2}{|c|}{ Titik Koordinat } & \multirow{2}{*}{$\begin{array}{c}\text { Ketinggian } \\
\text { (mdpl) }\end{array}$} & \multirow[b]{2}{*}{ Ket } \\
\hline & & $\mathrm{X}$ & $\mathrm{Y}$ & & \\
\hline 1 & LK1 & $5^{\circ} 05^{\prime} 150^{\prime \prime}$ & $120^{\circ} 06^{\prime} 706^{\prime \prime}$ & 289 & Tengah \\
\hline 2 & LK2 & $5^{\circ} 07^{\prime} 714^{\prime \prime}$ & $120^{\circ} 04^{\prime} 791^{\prime \prime}$ & 518 & Tengah \\
\hline 3 & LK3 & $5^{\circ} 08^{\prime} 809^{\prime \prime}$ & $120^{\circ} 03^{\prime} 657^{\prime \prime}$ & 402 & Tengah \\
\hline 4 & LK4 & $5^{\circ} 14^{\prime} 712^{\prime \prime}$ & $119^{\circ} 57^{\prime} 935^{\prime \prime}$ & 1359 & Hulu \\
\hline 5 & LK5 & $5^{\circ} 11^{\prime} 265^{\prime \prime}$ & $119^{\circ} 57^{\prime} 804^{\prime \prime}$ & 791 & Hulu \\
\hline 6 & LK6 & $5^{\circ} 18^{\prime} 810^{\prime \prime}$ & $119^{\circ} 56^{\prime} 775^{\prime \prime}$ & 2439 & Hulu \\
\hline
\end{tabular}




\begin{tabular}{cccccc}
7 & LK7 & $5^{\circ} 06^{\prime} 314^{\prime \prime}$ & $120^{\circ} 05^{\prime} 651^{\prime \prime}$ & 504 & Tengah \\
8 & LK8 & $5^{\circ} 07^{\prime} 344^{\prime \prime}$ & $120^{\circ} 05^{\prime} 723^{\prime \prime}$ & 553 & Tengah \\
9 & LK9 & $5^{\circ} 07^{\prime} 746^{\prime \prime}$ & $120^{\circ} 05^{\prime} 713^{\prime \prime}$ & 534 & Tengah \\
10 & LK10 & $5^{\circ} 15^{\prime} 058^{\prime \prime}$ & $119^{\circ} 58^{\prime} 101^{\prime \prime}$ & 1340 & Hulu \\
11 & LK11 & $5^{\circ} 14^{\prime} 987^{\prime \prime}$ & $119^{\circ} 58^{\prime} 218^{\prime \prime}$ & 1314 & Hulu \\
12 & LK12 & $5^{\circ} 15^{\prime} 059^{\prime \prime}$ & $119^{\circ} 58^{\prime} 348^{\prime \prime}$ & 1276 & Hulu \\
13 & LK13 & $5^{\circ} 14^{\prime} 666^{\prime \prime}$ & $119^{\circ} 57^{\prime} 913^{\prime \prime}$ & 1365 & Hulu \\
14 & LK14 & $5^{\circ} 09^{\prime} 503^{\prime \prime}$ & $120^{\circ} 03^{\prime} 348^{\prime \prime}$ & 438 & Tengah \\
15 & LK15 & $5^{\circ} 11^{\prime} 432^{\prime \prime}$ & $120^{\circ} 02^{\prime} 021^{\prime \prime}$ & 546 & Tengah \\
16 & LK16 & $5^{\circ} 09^{\prime} 843^{\prime \prime}$ & $120^{\circ} 03^{\prime} 286^{\prime \prime}$ & 417 & Tengah \\
17 & LK17 & $5^{\circ} 14^{\prime} 752^{\prime \prime}$ & $119^{\circ} 57^{\prime} 994^{\prime \prime}$ & 1360 & Hulu \\
\hline
\end{tabular}

Ket : LK (titik lokasi longsoran)

Berdasarkan Tabel 1 diketahui terdapat 8 titik longsoran pada bagian hulu dan 9 pada bagian hilir. Titik longsoran di hulu adalah LK4, LK5 dan LK6, LK 10, LK 11, LK 12, LK13 dan LK 17sedangkan dibagian tengah adalah LK1, LK2, LK3, LK7,LK8, LK9, LK14, LK15 dan LK 16. Sampel yang diamati sebanyak 6 titik longsoran yaitu LK1, merupakan perwakilan dari daerah bagian tengah dan hulu.Titik longsoran yang mewakili pada bagian tengah adalah longsoran LK1, LK2 dan LK3 dan titik longsoran yang mewakili pada bagian hulu adalah LK4, LK5 dan LK6.Tidak ditemukannya longsoran pada bagian hilir karena pada bagian ini merupakan daerah datar (lebih kecil dari $8 \%$ ).

\subsection{Jenis Longsoran}

Berdasarkan hasil pengamatan pada 6 titik longsor, terdapat 2 jenis longsoran yang ditemukan yaitu jenis translasi dan rotasi. Rekapitulasi hasil pengamatan pada 6 titik longsor tersebut disajikan pada Tabel 2.

Tabel 2. Jenis longsoran dan tutupan lahannya

\begin{tabular}{|c|c|c|c|}
\hline Jenis Longsoran & Penutupan Lahan & Lokasi & $\begin{array}{c}\text { Frekuensi } \\
\text { ditemukan (kasus) }\end{array}$ \\
\hline \multirow{3}{*}{ Translasi } & $\begin{array}{l}\text { Pertanian lahan kering } \\
\text { campur semak }\end{array}$ & $\begin{array}{l}\text { Kec. Bulupoddo } \\
\text { Kab. Sinjai }\end{array}$ & 1 \\
\hline & Semak & $\begin{array}{l}\text { Kec. Tombolo pao } \\
\text { Kab. Gowa }\end{array}$ & 1 \\
\hline & Belukar & $\begin{array}{l}\text { Kec. Sinjai barat } \\
\text { Kab. Sinjai }\end{array}$ & 1 \\
\hline \multirow{3}{*}{ Rotasi } & \multirow{3}{*}{$\begin{array}{l}\text { Pertanian lahan kering } \\
\text { campur semak }\end{array}$} & $\begin{array}{l}\text { Kec. Bulupoddo } \\
\text { Kab. Sinjai }\end{array}$ & 1 \\
\hline & & $\begin{array}{l}\text { Kec. Sinjai barat } \\
\text { Kab. Sinjai }\end{array}$ & 1 \\
\hline & & $\begin{array}{c}\text { Kec. Tombolo pao } \\
\text { Kab.Gowa }\end{array}$ & 1 \\
\hline $\begin{array}{l}\text { Jenis long } \\
\text { lasi.Longsoran } \\
\text { bidang gelincir } \\
\text { kering campur } \\
\text { h lereng.Sketsa }\end{array}$ & $\begin{array}{l}\text { yang ditemukan pa } \\
\text { adalah longsoran yang } \\
\text { entuk cekung. Tata gur } \\
\text { pada bagian atas lerer } \\
\text { hana lokasi longsoran d }\end{array}$ & $\begin{array}{l}\text { lokasi penelitian ya } \\
\text { di dengan berpindahn } \\
\text { ahan padalongsoran je } \\
\text { an infrasturktur jalan s } \\
\text { condisi di sekitarnya da }\end{array}$ & $\begin{array}{l}\text { longsoran rotasi dan } \\
\text { nassa tanah dan batuan } \\
\text { rotasi berupa pertanian } \\
\text { pemukiman pada bagian } \\
\text { dilihat pada Gambar } 1 .\end{array}$ \\
\hline
\end{tabular}




\section{学}

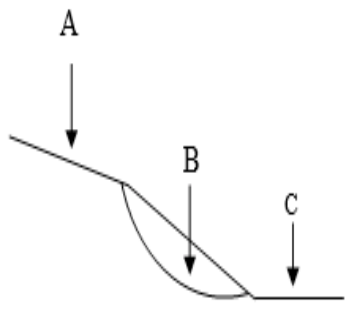

Ket :

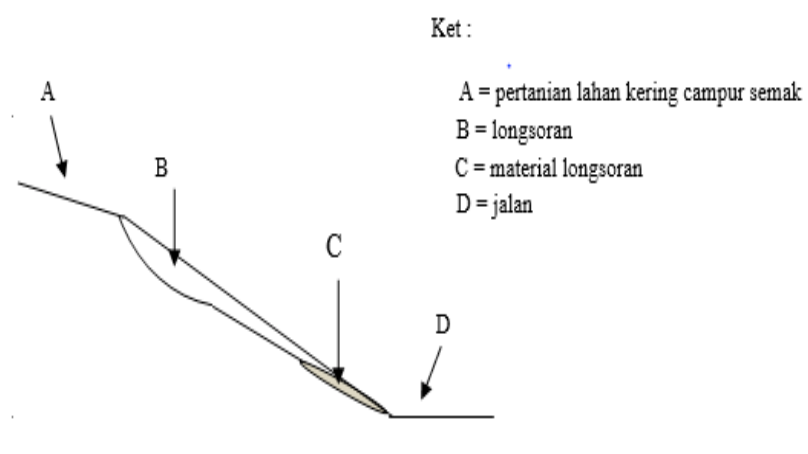

(a)
Jurnal Hutan dan Masyarakat. Vol. 10 (1): 203-214, Juli 2018 Diserahkan: 2018-05-24; Diterima: 2018-07-30

ISSN: 1907-5316 ISSN ONLINE: 2613-9979

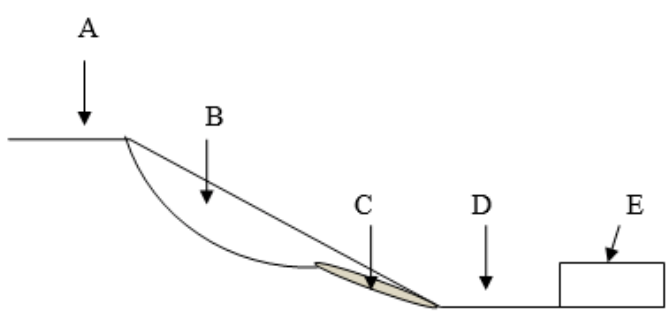

Ket :

$A=$ pertanian lahan kering campur semak

$\mathrm{B}=$ longsoran

$\mathrm{C}=$ material longsoran
$\mathrm{D}=$ jalan $\mathrm{E}=$ pemukiman

$$
\begin{aligned}
\text { Ket }: & \\
A & =\text { pertanian lahan kering campur semak } \\
B & =\text { longsoran dan material } \\
C & =\text { jalan }
\end{aligned}
$$

(b)

(c)

Gambar 1. a (Longsoran jenis rotasi 1), b (Longsoran jenis rotasi 2), c (Longsoran jenis rotasi 3)

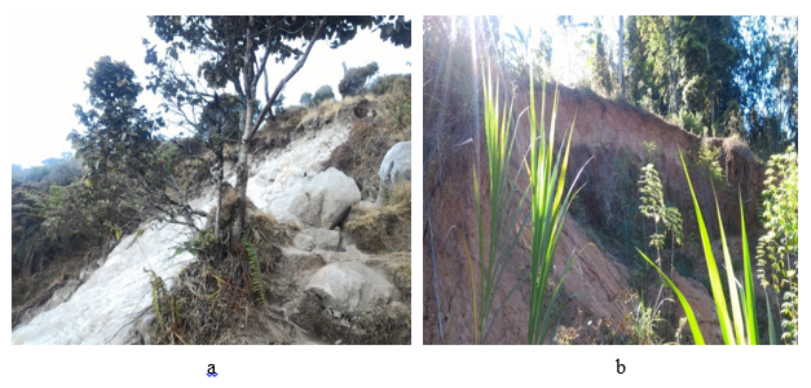

Gambar 2. (a) Longsoran translasi, (b) Longsoran rotasi

Jenis longsoran translasi adalah berpindahnya massa tanah dan batuan pada bidag gelincir yang berbentuk rata atau menggelombanglandai. Tata guna lahan pada longsorantranslasi yang ditemukan di lokasi penelitian yaitu berupa sawah dan infrastuktur jalan pada bagian atas lereng sedangkan pada bagian bawah lereng berupa sawah dan infrastruktur jalan.Sketsa sederhana lokasi longsoran dan kondisi di sekitarnya dapat dilihat pada Gambar 3.
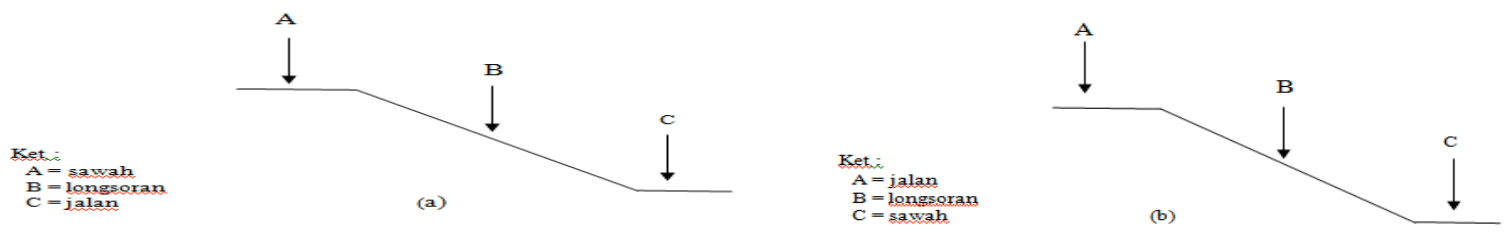

Gambar 3. a (Longsoran jenis translasi 1), b (Longsoran jenis translasi 2) 


\subsection{Karakteristik Longsor}

Karakteristik jenis longsoran yang ditemukan di lokasi penelitian yaitu, longsoran rotasi memiliki karakteristik gerakan tanah luncuran ke bawah berupa material tanah atau batuan pada bidang gelincir dari tempat yang tinggi ke tempat yang rendah berbentuk cekung. Pada titik LK1, LK3 dan LK4 jenis longsoran yang ditemukan yaitu longsoran rotasi dengan bidang gelincir berbetukcekung, material longsoran berupa tanah dan batuan, vegetasi berupa langsat, aren, sengon, jelutung, semak, bambu, paku, tekstur tanah lempungberpasir dan memiliki volume longsoran sebesar LK1 $\left(290 \mathrm{~m}^{3}\right)$, LK3 $(4.326,87$ $\left.\mathrm{m}^{3}\right)$ dan LK4 (41.14 $\left.\mathrm{m}^{3}\right)$.

Longsoran translasi memiliki karakteristik massa tanah dan batuan yang bergerak pada bidang gelincir berbentuk rata atau menggelombanglandai. Pada titik LK2, LK5 dan LK6 jenis longsoran yang ditemukan yaitu longsoran translasi dengan bidang gelincir yang berbentuk rata atau menggelombanglandai, material longsoran tanah dan batuan, vegetasi berupa cengkeh, jati, singkong, aren, paku-pakuan, pisang dan tekstur tanah pasir berlempung dan liat berlempungdan memiliki volume longsoran sebesar LK2(1.927,8 m³), LK5 (43.29 m³) dan LK6 $\left(845.25 \mathrm{~m}^{3}\right)$.

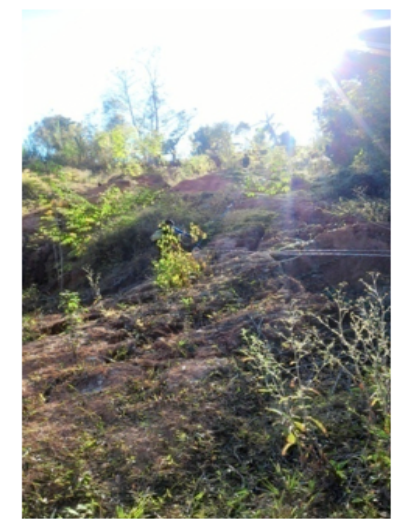

(a)

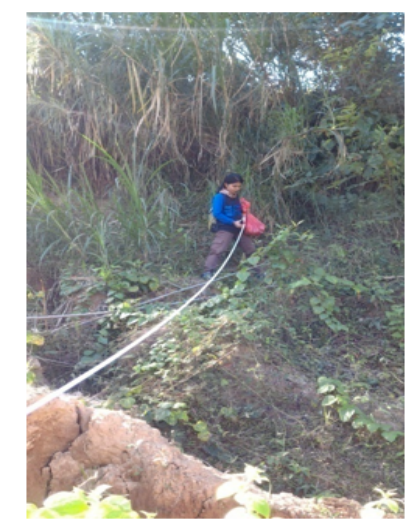

(b)

Gambar 4.a (Gambar dimensi longsoran), (b) Pengukuran dimensi longsoran

\subsection{Faktor-Faktor Penyebab Terjadinya Tanah Longsor}

\section{a. Tutupan Lahan}

Berdasarkan hasil pengamatan lapangan diketahui bahwa area kejadian longsor di DAS Tangka ditemukan pada 3 jenis penutupan lahan yaitu pertanian lahan kering campur semak, semak dan belukar.Sebaran penutupan lahan, lokasi dan frekuensi ditemukannya kejadian longsoran tertera pada Tabel 3.

Tabel 3. Jenis penutupan vegetasi di lokasi kejadian longsoran

\begin{tabular}{ccc}
\hline Penutupan Lahan & Lokasi & $\begin{array}{c}\text { Jumlah Lokasi } \\
\text { Longsoran }\end{array}$ \\
\hline Pertanian lahan kering & Kec. Bulupoddo, Kab. Sinjai & 2 \\
campur semak & Kec. Sinjai barat, Kab. Sinjai & 1 \\
& Kec. Tombolo pao Kab.Gowa & 1 \\
\hline Semak & Kec. Tombolo pao Kab.Gowa & 1 \\
\hline Belukar & Kec. Sinjai barat, Kab. Sinjai & 1 \\
\hline
\end{tabular}


Pada lokasi pertanian lahan kering campur semak diketahui bahwa kasus longsor terjadi sebanyak 4 kali kejadian. Hal ini disebabkan karena faktor penyebab dari tanah longsor yaitu, jenis batuan dan tekstur tanahnya. Pada tutupan lahan pertanian lahan kering campur semak jenis batuan yang ditemukan adalah andesit dan tufa dimana sifat dari batuan tufa yaitu batuannya mudah lapuk dari lapuk tinggi sampai lapuk sempurna dan batuan andesit memiliki sifat yang kedap air, sehingga menampung air dan dapat menjadi bidang gelincir. Pada tutupan lahan pertanian lahan kering campur semak ini memiliki tekstur tanah lempung berpasir dan pasir berlempung.

Kejadian longsoran terletak di Kecamatan Bulupoddo Kabupaten Sinjai, Kecamatan Sinjai Barat Kabupaten Sinjai dan Kecamatan Tombolo Pao Kabupaten Gowa.Jenis tanaman yang terdapat pada pertanian lahan kering campur semak ini terdiri atas tanaman semusim berupa singkong, pisang, pakupakuan, aren, bambu dan tanaman tahunan berupa jati, langsat, cengkeh, sengon dan jelutung.Kejadian longsor tersebut dipengaruhi oleh faktor penyebab erosi yaitu curah hujan, kemiringan lereng dan jenis tanah.Kemiringan lereng pada tiap kejadian longsor termasuk dalam klasifikasi terjal yaitu $62.4 \%, 93.2 \%$, $83.9 \%, 86.9 \%, 96.5 \%$ dan $100 \%$. Hal ini menyebabkan longsor pada lokasi tersebut karena keadaan lereng yang terjal dan curah hujan yang tinggi. Kecamatan Bulupoddo Kabupaten Sinjai, termasuk dalam DAS Tangka, yang memiliki iklim basah (Tipe B) sehingga mendukung terjadinya longsor. Sesuai dengan pernyataan Efendi (2008) bahwa curah hujan yang tinggi menentukan terjadi atau tidaknya longsor pada daerah terjal.

Penutupan lahan selanjutnya yang ditemukan pada lokasi kejadian longsor yang berada di Kecamatan Tinggimoncong Kabupaten Gowa dan Kecamatan Tombolo Pao Kabupaten Gowa yaitu semak dan belukar.Jenis tanaman yang tumbuh pada daerah longsoran ini berupa bambu, semak dan paku-pakuan. Semak mudah terjadi longsor karena akarnya yang kurang dalam untuk mengikat atau mencengkram tanah. Minimnya penutupan lahan dan vegetasi, membuat perakaran sebagai pengikat tanah menjadi berkurang dan mempermudah tanah menjadi retak pada musim kemarau dan pada musim penghujan air akan mudah meresap ke dalam lapisan tanah melalui retakan tersebut dan menyebabkan lapisan tanah menjadi jenuh air, cepat atau lambat hal ini yang mengakibatkan longsor terjadi. Sawah, semak belukar, pertanian lahan kering mudah terjadi longsor ini sesuai dengan pendapat Wahyunto (2007), bahwa penggunaan lahan seperti persawahan maupun tegalan dan semak belukar, terutama pada daerah-daerah yang mempunyai kemiringan lahan terjal umumnya sering terjadi tanah longsor.

Penutupan lahan di lokasi penelitian yang berupa pertanian lahan kering campur semak, semak dan belukar turut memicu terjadinya longsor. Oleh karena itu perlu dilakukan penanaman pohon. Menurut Efendi (2008) tanaman yang cocok ditanam berupa tanaman keras dan berakar tunggang seperti kemiri, johar, lamtoro merah, mahoni, angsana, asam jawa, sonokeling, jati, pinus, akasia, kemiri, damar dan jenis bambu untuk daerah yang berlereng curam. Pemilihan jenis pohon harus disesuaikan dengan kondisi tiap daerah dan memperhatikan aspek geologi, ekonomi dan kelerengannya.Vegetasi di atas tanah berfungsi untuk mencengkram dan menjangkar tanah. Tidak adanya vegetasi akan menghilangkan fungsi dari vegetasi yang berperan mengikat tanah dan akibat jika gaya pendorong meningkat maka akan mudah terjadi longsor.

\section{b. Kemiringan Lereng}

Hasil pengamatan pada lokasi penelitian menunjukkan kemiringan lereng mulai dari $62.4 \%$ sampai dengan $100 \%$.Dari hasil pengamatan dapat dilakukan pengkategorian kemiringan lereng dari klasifikasi datar/landai sampai terjal berdasarkan tabel klasifikasi kelerengan menurut Kementrian Kehutanan (2013).

Berdasarkan pengamatan langsung di lokasi penelitian diperoleh kelerengan yang tidak bervariasi, hanya satu kemiringan lereng dengan klasifikasi terjal.Kelerengan pada LK1 adalah $62.4 \%$, LK2 93.2\%, LK3 83.9\%, LK4 86.9\%, LK5 96.5\%, dan LK6 100\%.Dari hasil kelerengan yang ditunjukkan pada Tabel 4, titik longsoran pada lokasi penelitian termasuk dalam kelas 5 dengan klasifikasi terjal. Klasifikasi kelerengan di lokasi penelitian dapat dilihat pada Tabel 4. 
Tabel 4. Klasifikasi kelerengan di lokasi penelitian

\begin{tabular}{cccc}
\hline Label & Lereng $(\%)$ & Kelas & Klasifikasi \\
\hline LK1 & 62.4 & 5 & Terjal \\
LK2 & 93.2 & 5 & Terjal \\
LK3 & 83.9 & 5 & Terjal \\
LK4 & 86.9 & 5 & Terjal \\
LK5 & 96.5 & 5 & Terjal \\
LK6 & 100 & 5 & Terjal \\
\hline
\end{tabular}

Ket: $L K$ (titik lokasi longsoran)

Kelerengan sangat berpengaruh besar terhadap terjadinya tanah longsor, semakin terjal kemiringan lereng akan semakin besar peluang untuk terjadinya tanah longsor. Hal ini sesuai dengan pendapat Sumiyatinah dan Yohanes (2000), yang menyatakan bahwa tanah longsor umumnya dapat terjadi pada wilayah berlereng, makin tinggi kemiringan lahannya akan semakin besar potensi longsornya.

Lereng yang rentan akan tanah longsor umumnya memiliki tutupan vegetasi berupa tanaman yang berakar serabut, tetapi tidak menutup kemungkinan lereng yang ditanami dengan vegetasi pohon yang massanya besar dengan jarak tanam yang rapat terlepas dari potensi bencana tanah longsor. Meskipun tajuk pohon dan tanaman bawah seperti rumput mampu mengurangi kekuatan energi kinetik pada saat hujan terjadi, tetapi hal itu kurang efektif ketika terjadi hujan lebat dalam waktu yang relatif lama. Namun, tidak semua lahan dengan kondisi miring mempunyai potensi untuk longsor, hal ini tergantung pada karakter lereng terhadap respon tenaga pemicu terutama respon lereng terhadap curah hujan.

Unsur topografi yang paling besar pengaruhnya terhadap bencana longsor adalah kemiringan lereng.Kemiringan lereng sangat berpengaruh terhadap longsor, dimana makin curam lereng, makin besar dan makin cepat longsor terjadi.Kemiringan dan panjang lereng juga merupakan 2 unsur topografi yang paling berpengaruh terhadap aliran permukaan dan erosi (Arsyad, 2010).

Hardjowigeno (1992) menyatakan bahwa erosi akan meningkat apabila lereng semakin curam atau semakin panjang, apabila lereng semakin curam maka kecepatan aliran permukaan meningkat, sehingga kekuatan mengangkut meningkat pula, dan lereng yang semakin panjang menyebabkan volume air yang mengalir menjadi semakin besar. Selanjutnya, Wahyunto (2007) menambahkan bahwa tanah longsor umumnya dapat terjadi pada wilayah berlereng, makin tinggi kemiringan lerengnyaakan semakin besar potensi tanah longsornya.

\section{c. Karakteristik Tanah}

Untuk mengetahui karakteristik tanah pada titik lokasi longsoran, dilakukan analisis tanah di Laboratorium Silvikultur Jurusan Kehutanan Fakultas Kehutanan Universitas Hasanuddin.Hasil analisis tanah dapat dilihat pada Tabel 5 .

Tabel 5. Hasil analisis tanah

\begin{tabular}{|c|c|c|c|c|c|c|c|}
\hline \multirow{2}{*}{ Label } & \multirow{2}{*}{$\begin{array}{l}\text { Luas } \\
\left(\mathbf{m}^{2}\right)\end{array}$} & \multirow{2}{*}{ Kelas Tekstur } & \multicolumn{3}{|c|}{$\%$} & \multirow{2}{*}{ Jenis Tanah } & \multirow{2}{*}{$\begin{array}{c}\text { Nilai } \\
\mathbf{K}\end{array}$} \\
\hline & & & Pasir & Debu & Liat & & \\
\hline LK1 & 232 & Lempung Berpasir & 47 & 36 & 17 & Dystropepts & 0.21 \\
\hline LK2 & 550.8 & Pasir Berlempung & 70 & 20 & 10 & Dystropepts & 0.21 \\
\hline LK3 3 & 1236.25 & Lempung Berpasir & 31 & 45 & 24 & Dystropepts & 0.21 \\
\hline LK4 & 54.86 & Lempung Berpasir & 54 & 28 & 18 & Dystrandepts & 0.31 \\
\hline LKS & 78.72 & Lempung Berliat & 37 & 36 & 27 & Dystropepts & 0.21 \\
\hline LK6 & 676.2 & Pasir Berlempung & $\mathbf{s 5}$ & 9 & 6 & Dystrandepts & 0.31 \\
\hline
\end{tabular}


Karakteristik tanah pada lokasi penelitian umumnya bertektur tanah yang mengandung pasir dengan jenis tanah dystropepts dan distrandept. Persentase kandungan pasir bervariasi dari $31-85 \%$. Kondisi tekstur seperti ini memungkinkan tanah mudah meloloskan air. Tekstur tanah yang mendominasi pada lokasi longsor yang diteliti yaitu tekstur tanah lempung berpasir dengan jenis tanah dystropepts pada LK1 dan LK3 dan jenis tanah dystrandepts pada LK4 dan LK6.

Tanah lempung merupakan jenis tanah yang memiliki banyak lempung dan sedikit pasir, jenis tanah ini merupakan tanah yang mudah menyerap air dalam kondisi kering.Lempung memiliki potensi untuk terjadinya tanah longsor terutama pada saat hujan.Jenis tanah yang bersifat lempung, lanau dan pasir memiliki sifat yang mudah meloloskan air.

Sifat tanah seperti lempung, lanau dan pasir akan menambah bobot tanah pada saat hujan dan akan memudahkan terjadinya longsor. Jika pada lahan tersebut tidak ada pohon yang berakar dalam dan tahan terhadap angin, maka akan mudah terjadi longsor, sedangkan tanah dengan tekstur pasir berlempung merupakan tanah yang memiliki banyak pasir dengan sedikit lempung. Dimana tanah jenis ini juga mampu meloloskan air dengan cepat, tanah seperti ini bersifat lepas, tidak lekat, serta laju infiltrasi dan perkolasinya cepat.

Kejadian longsor di lokasi penelitian didukung dengan nilai erodibilitas atau nilai kepekaan erosi tanahnya yang berkategori sedang dan besar.Pada jenis tanah dystrandepts nilai erodibilitas atau nilai kepekaan erosi tanahnya yaitu sebesar 0.31 sedangkan pada jenis tanah dystropepts 0.21 . Nilai erodibilitas pada lokasi penelitian menunjukkan nilai yang besar, jika nilai erodibilitas besar maka longsor akan mudah terjadi. Seperti yang dikatakan Sitorus, (2006) bahwa nilai kepekaan erosi tanah (K) menunjukkan mudah tidaknya tanah mengalami erosi, ditentukan oleh berbagai sifat fisik dan kimia tanah. Makin kecil nilai K makin tidak peka suatu tanah terhadap erosi.

\section{d. Infiltrasi}

Hasil pengukuran laju infiltrasi pada lokasi longsoran diperoleh nilai sebesar $71.4 \mathrm{~cm} / \mathrm{jam}$ sampai dengan $212.4 \mathrm{~cm} / j a m$ dengan kriteria laju infiltrasi sangat cepat. Klasifikasi laju Infiltrasi dari 6 titik pengamatan dapat dilihat pada Tabel 6 .

Tabel 6. Klasifikasi laju infiltrasi

\begin{tabular}{cccl}
\hline Label & Cm/menit & Cm/jam & Kriteria \\
\hline LK1 & 1.19 & 71.4 & Sangat Cepat \\
LK2 & 2.18 & 130.8 & Sangat Cepat \\
LK3 & 9.97 & 598.2 & Sangat Cepat \\
LK4 & 3.83 & 229.8 & Sangat Cepat \\
LK5 & 6.21 & 372.6 & Sangat Cepat \\
LK6 & 3.54 & 212.4 & Sangat Cepat \\
\hline
\end{tabular}

Ket : $L K$ (titik lokasi longsoran)

Berdasarkan kriteria laju infiltrasi pada setiap longsoran yang disajikan pada Tabel 6, laju infiltrasi pada setiap longsoran yaitu sangat cepat maka dapat diprediksi bahwa pada lokasi penelitian ini rawan longsor.Hal ini disebabkan karena tekstur tanah yang ada pada lokasi penelitian yaitu berupa lempungberpasir dan pasir berlempung, dimana jenis tanah ini merupakan jenis yang mudah meloloskan air dengan cepat.Nilai laju infiltrasi bergantung pada kondisi tanah dan kapasitas hujan. Tanah dalam kondisi kering memiliki daya serap yang tinggi sehingga laju infiltrasi semakin besar dan akan berkurang perlahan-lahan apabila tanah tersebut jenuh terhadap air.

Selain itu yang dapat menyebabkan terjadinya infiltrasi sangat cepat yaitu, keadaan vegetasinya.Hal ini sejalan dengan penelitian Juanda (2015) yang menyatakan bahwa, tanah bervegetasi lebih rapat cenderung memiliki laju infiltrasi lebih tinggi dibandingkan dengan tanah dengan vegetasi yang kurang rapat dan yang bervegetasijarang.Keanekaragaman jenis vegetasi, ketebalan serasah, dan 
lapisan tajuk dapat memberikan pengaruh pergerakan air mulai dari turunnya curah hujan dari atmosfer ke permukaan tanah dan sampai pada lapisan tanah.

Penelitian yang dilakukan Setiawan, (2012) mengenai Sistem Perakaran Bidara Laut Untuk Pengendalian Tanah Longsor bahwa bidara laut pada tingkat semai dan pancang mampu menembus lapisan top soil saja dengan kondisi lapisan tanah yang tipis.Pada kondisi ini peran bidara laut dalam pengendalian tanah longsor relatif tidak besar. Pada tingkat tiang dan pohon, akar bidara laut mampu menembus sampai dua lapisan tanah. Akar yang mampu menembus lapisan permukaan sampai dengan lapisan tanah kuat di bawahnya akan menambah kuat geser tanah sesuai kedalamannya.

Arsitektur tipe-R merupakan tipe yang paling efektif dalam meningkatkan kekuatan geser tanah. Hasil penelitian Fan dan Yu-wen dalam Setiawan, $O$ (2012) terhadap lima jenis tanaman dengan arsitektur perakaran yang berbeda menunjukkan bahwa tipe-R memberikan peningkatan kuat geser lebih besar dibandingkan dengan tipe lainnya. Untuk itu perlu ditanami pepohonan yang memiliki akar panjang dan bermanfaat di lokasi longsoranuntuk menstabilkan lereng juga tahan terhadap angin.Jenis pohon yang sesuai ditanam pada areal lokasi longsoran yaitu asam jawa, jati, mahoni, johar, pinus, dan lain sebagainya.

\section{e. Curah Hujan}

Data curah hujan pada lokasi penelitian dapat dikategorikan dari klasifikasi sangat rendah sampai sangat tinggi berdasarkan tabel klasifikasi curah hujan menurut Kementrian Kehutanan (2013).

Data curah hujan 10 tahun terakhir yang diperoleh dari The Nasional Centre For Environmental Prediction yang diunduh melalui www.globalweather.tamu.edu dan ditunjukkan pada Tabel 7 memiliki curah hujan $3646 \mathrm{~mm} /$ tahun, $2512 \mathrm{~mm} /$ tahun dan $2688 \mathrm{~mm} /$ tahun dengan klasifikasi sangat tinggi dan sedang/tinnggi. Tipe iklim di DAS Tangka termasuk tipe iklim basah dengan nilai $Q$ sebesar $21,05 \%$, $24,73 \%$ dan 29,54\%. Klasifikasi curah hujan dapat dilihat pada Tabel 7 .

Tabel 7. Klasifikasi curah hujan

\begin{tabular}{cccc}
\hline No & Stasiun curah Hujan & $\begin{array}{c}\text { Curah hujann } \\
\text { (mm tahun) }\end{array}$ & Klasifikasi \\
\hline 1 & Weatherdata-521200 & 3646 & Sangat tinggi \\
2 & Weatherdata-521203 & 2512 & Sedang tinggi \\
3 & Weatherdata-551200 & 2688 & Sedang tinggi \\
\hline
\end{tabular}

Curah hujan merupakan salah satu faktor pemicu terjadinya tanah longsor. Curah hujan yang tinggi akan menentukan terjadi atau tidaknya longsor pada daerah terjal. Jika hujan deras berlangsung beberapa jam hingga beberapa hari dan disusul dengan hujan deras sesaat, maka kejadian longsor akan mudah terjadi. Hal ini juga didukung oleh pernyataan Efendi (2008), bahwa faktor curah hujan yang berpengaruh terhadap bahaya longsoran adalah besarnya curah hujan, intensitas curah hujan, dan distribusi curah hujan. Curah hujan dapat mempengaruhi kadar air di dalam tanah. Semakin tinggi curah hujan maka kadar air dalam tanah pun tinggi, hal ini menyebabkan kuat geser lereng menurun karena meningkatnya massa tanah akibat tanah jenuh air. Kondisi ini menyebabkan menurunnya nilai kohesi, agregat tanah mudah lepas dan memicu terjadinya gerakan tanah dan longsor.

Air hujan yang menimpa tanah-tanah terbuka akan menyebabkan tanah terdispersi, selanjutnya sebagian dari air hujan yang jatuh tersebut akan mengalir di atas permukaan tanah. Banyaknya air yang mengalir di atas permukaan tanah tergantung pada kemampuan tanah untuk menyerap air (kapasitas infiltrasi). Oleh karena itu, untuk mencegah agar tanah tidak terdispersi, maka perlu adanya vegetasi yang menutupi permukaan tanah, sehingga air yang turun diserap dan disimpan oleh vegetasi tersebut. 


\section{f. Geologi}

Hasil penelitian pada lokasi longsoran menunjukkan bahwa jenis batuan yang ditemukan ada dua yaitu jenis batuan andesit dan tufa yang dapat dilihat pada Tabel 8 .

Jenis batuan tufa merupakan batuan piroklasik yang disusun oleh material hasil gunung api yang banyak mengandung debu vulkanik dan meniral gelas, dengan warna putih kekurangan, abu-abu dan kuning kecoklatan dan jenis batu andesit adalah jenis batuan yang secara sederhananya dikatakan batu ini berasal dari lahar yang dihasilkan gunung berapi yang membeku. Batu dengan jenis andesit ini biasanya memiliki karakter yang khas dengan warna abu-abu yang terang hingga berwarna gelap.

Tabel 8. Jenis batuan pada lokasi longsoran

\begin{tabular}{ccc}
\hline Label & Jenis Batuan & Lokasi Kejadian Longsor \\
\hline LK1 & Andesit & Kec. Bulupoddo Kab. Sinjai Sinjai \\
LK2 & Tufa & Kec. Bulupoddo Kab. Sinjai Sinjai \\
LK3 & Andesit & Kec. Sinjai barat Kab. \\
LK4 & Andesit & Kec. Tombolo pao Kab.Gowa \\
LK5 & Tufa & Kec. Tombolo pao Kab.Gowa \\
LK6 & Andesit & Kec. Sinjai barat Kab.Sinjai \\
\hline
\end{tabular}

Endapan vulkanik merupakan batuan yang mudah lapuk terutama tufa yang lapuk tinggi sampai lapuk sempurna, sehingga pada saat musim hujan air akan meresap ke dalam batuan dan menyebabkan massa batuan bertambah berat sehingga berpotensi terjadi tanah longsor. Andesit merupakan batuan yang memiliki sifat yang kedap air sehingga menampung air dan tidak bisa meloloskan air, akibatnya batuan tersebut dapat dijadikan sebagai bidang gelincir.

Batuan yang kurang kuat umumnya batuan gunung api dan batuan sedimen berukuran pasir dan campuran pasir, krikil, dan liat yang kurang kuat merupakan salah satu dari faktor penyebab tanah longsor. Faktor tekstur tanah turut berperan sebagai pemicu longsor dalam kaitannya dengan kondisi geologiyang ada. Tanah bertekstur lempung berpasir dan dikombinasikan dengan batuan induk bersifat andesit, basalt, atau breksi, serta dengan kemiringan yang curam, maka akan menjadikan daerah tersebut rawan longsor. Tanah bertekstur pasir berperan dalam meningkatkan infiltrasi tanah. Jika tanah dalam keadaan jenuh air, massa tanah akan menjadi lebih berat.

Jenis tanah yang bersifat lempung, lanau, pasir, merupakan jenis tanah yang mudah meloloskan air. Sifat tersebut menjadikan tanah bertambah berat bobotnya jika tertimpa hujan. Apabila tanah tersebut berada di atas batuan kedap air pada kemiringan tertentu maka air yang masuk akan tertahan dan tanah pada kemiringan tertentu akan berpotensi menggelincir menjadi longsor (Efendi, 2008).

Menurut Wilopo dan Priyono (2005), batuan formasi andesit dan breksi merupakan faktor pemicu terjadinya longsor karena sifatnya yang kedap air. Sehingga batuan yang bersifat andesit dan breksi tersebut dapat dijadikan sebagai bidang gelincir untuk terjadinya longsor. Dalam keadaan jenuh air pada musim hujan, ditambah dengan tekstur tanah lempung pasiran maka pada daerah yang memiliki batuan induk bersifat andesit menjadi rawan longsor.

\section{KESIMPULAN DAN SARAN}

\subsection{Kesimpulan}

Berdasarkan hasil penelitian yang diperoleh maka dapat ditarik kesimpulan bahwa:

a. Jenis longsoran yang ditemukan pada lokasi penelitian yaitu jenis longsoran translasi dan rotasi.

b. Tidak ada perbedaan jenis tanah, laju infiltrasi, vegetasi, geologi, kelerengan dan curah hujan pada kedua jenis longsoran yang ditemukan. 


\subsection{Saran}

Perlu dilakukan penelitian lebih lanjut tentang porositas, bulk density, kedalaman tanah, permeabilitas dan bahan organik agar lebih mudah untuk mengetahui penyebab tanah longsor.

\section{DAFTAR PUSTAKA}

Arsyad, S. 2010. Konservasi Tanah dan Air. IPB Press. Bogor.

Candra, W. 2014.Wilayah Adat Patalassang Longsor, Puluhan Hektar Sawah Hancur dalamhttp://www.mongabay.co.id/2014/05/12/wilayah-adat-patalassang-longsor-puluhan-hektarsawah-hancurl, diakses pada 10 Maret 2015.

Efendi, A. 2008.Identifikasi Kejadian Longsor dan Penentuan Faktor-Faktor Utama Penyebabnya di Kecamatan Babakan Madang Kabupaten Bogor. Bogor.

Hardjowigeno, S. 1992. IImu Tanah. Jakarta : Akademika Pressindo.

Juanda, F. 2015. Laju Infiltrasi Pada Hutan Alam di Sub Daerah Aliran Sungai Lengkese Hulu DAS Jeneberang. Skripsi. Fakultas Kehutanan Universitas Hasanuddin. Makassar.

Kementrian Kehutanan Peraturan Direktur Jendral Bina Pengelolaan Daerah Aliran Sungai Dan Perhutanan Sosial. 2013. Nomor p.3/v-set/ Tentang Pedoman Identifikasi Karakteristik Daerah Aliran Sungai. Hal 8 dan 21.

Maniskari,G.2013. Infiltrasi.http://www.foresindonesia.blogspot.com. Diakses pada 12 Maret 2015

Setiawan, O. 2012.Sistem Perakaran Bidara Laut (Strychnoslucida R.Br.) Untuk Pengendalian Tanah Longsor.

Sitorus, Santun R. P. 2006. Pengembangan Lahan Berpenutupan Tetap Sebagai Kontrol Terhadap Faktor Resiko Erosi dan Bencana Longsor. Direktorat Jenderal Penataan Ruang Departemen Pekerjaan Umum. Jakarta.

Sumiyatinah dan Yohanes.2000.Pemodelan SIG untuk menentukan daerah rawan erosi akibat longosran di Propinsi Jawa Barat, dalamProsiding "Forum IImiah Tahunan Ikatan Surveyor Indonesia.lkatan Surveyor Indonesia. Bandung.

Wahyunto. 2007. Kerawanan Longsor Lahan Pertanian Di Daerah Aliran Sungai Citarum.Jawa Barat. Balai Penelitian Tanah. Bogor.

Wilopo, W,Suryanto, P. 2005. Agroforestri Alternatif Model Rekayasa Vegetasi Pada Kawasan Rawan Longsor. J Hutan Rakyat 